\title{
Intragenomic polymorphisms among high-copy loci: A genus- wide study of nuclear ribosomal DNA in Asclepias (Apocynaceae)
}

Kevin Weitemier, Shannon C. K. Straub, Mark Fishbein, Aaron Liston

Despite knowledge that concerted evolution of high-copy loci is often imperfect, few studies investigate the extent of intragenomic polymorphisms and comparisons across a large number of species are rarely made. We present a bioinformatic pipeline for characterizing polymorphisms within an individual among copies of a high-copy locus. Results are presented for nuclear ribosomal DNA ( $\mathrm{nrDNA}$ ) across the milkweed genus, Asclepias. The 18S-26S portion of the nrDNA cistron of Asclepias syriaca served as a reference for assembly of the region from 124 samples representing 90 species of Asclepias. Reads were mapped back to each individual's consensus and at each position reads differing from the consensus were tallied using a custom perl script. Low frequency polymorphisms existed in all individuals (mean $=5.8 \%$ ). Most nrDNA positions $(91 \%)$ were polymorphic in at least one individual, with polymorphic sites being less frequent in subunit regions and loops. Highly polymorphic sites existed in each individual, with highest abundance in the "noncoding" ITS regions. Phylogenetic signal was present in the distribution of intragenomic polymorphisms across the genus. Intragenomic polymorphisms in nrDNA are common in Asclepias, being found at higher frequency than any other study to date. The high and variable frequency of polymorphisms across species highlights concerns that phylogenetic applications of nrDNA may be error-prone. The new analytical approach provided here is applicable to other taxa and other high-copy regions characterized by low coverage genome sequencing (genome skimming). 

ribosomal DNA in Asclepias (Apocynaceae) Corvallis, OR 97331 USA; ${ }^{3}$ Department of Biology, Hobart and William Smith Colleges, 300 Pulteney Street, Geneva, NY 14456 USA; and ${ }^{4}$ Department of Botany, Oklahoma State University, 301 Physical Sciences, Stillwater, OK 74078 USA

8 Email addresses:

KW: kevin.weitemier@science.oregonstate.edu

SCKS: straub@hws.edu

11 MF: mark.fishbein@okstate.edu

AL: listona@science.oregonstate.edu

1 1Author for correspondence: kevin.weitemier@science.oregonstate.edu, 541-737-5275 


\section{INTRODUCTION}

14 With the advent of DNA sequencing technology to infer phylogenetic relationships,

15 investigators began searching for genetic loci that were both phylogenetically informative and

16 readily sequenced in most organisms. The use of nuclear ribosomal DNA (nrDNA) soon became

17 a popular choice for phylogenetic inference (Hamby \& Zimmer, 1988; Hillis \& Dixon, 1991;

18 Baldwin, 1992; Baldwin et al., 1995; Álvarez \& Wendel, 2003). Nuclear ribosomal DNA offered

19 several advantages over other loci: the combination of highly conserved and variable regions

20 allowed phylogenetic inference across a broad range of evolutionary time scales, conserved

21 regions allowed the use of "universal" PCR primers applicable to a wide range of taxa, the high

22 copy number of nrDNA repeats allowed reliable amplification from lower quality DNA

23 extractions, and the process of concerted evolution ensured that these copies were similar within

24 individuals (Baldwin et al., 1995). The use of nrDNA, particularly the variable internal

25 transcribed spacer (ITS) regions, became widespread, to the extent that many studies were based

26 exclusively on ITS data (Álvarez \& Wendel, 2003). 
However, nrDNA loci have been shown to harbor limitations in their phylogenetic utility.

28 Nuclear ribosomal DNA copies are assembled as tandem repeats at one or more loci in the

29 genome, with each locus being known as an array. The number of repeats present within an array

30 is labile, as is the number and location of arrays (Álvarez \& Wendel, 2003). The process of

31 nrDNA copy homogenization from homologous recombination or unequal crossing over is

32 thought to occur much more frequently within than among arrays (Schlötterer \& Tautz, 1994).

33 Thus, differing nrDNA alleles may become fixed in different arrays within a genome, creating

34 paralogy that, if unrecognized, may confound phylogenetic inference (Álvarez \& Wendel, 2003;

35 Song et al., 2012). Moreover, these events can create pseudogenes which, freed from selective

36 pressures, may evolve through processes quite different from the functional loci and provide

37 misleading evidence for between-individual genetic divergences if compared to functional copies

38 (Buckler, Ippolito \& Holtsford, 1997). These events may occur at a greater rate than inter-array

39 homogenization via concerted evolution (Karvonen \& Savolainen, 1993; Gernandt \& Liston,

40 1999). 
41 Due to the technical difficulty of systematically sequencing individual nrDNA loci

42 because of their high copy number, studies characterizing the abundance and patterns of

43 intragenomic nrDNA polymorphisms have been rare. Recently, studies utilizing whole-genome

44 shotgun sequencing have begun to reveal levels of intragenomic polymorphism in Drosophila

45 (Stage \& Eickbush, 2007), nematodes (Bik et al., 2013), and fungi (Ganley \& Kobayashi, 2007).

46 However, these studies included a small number of species (12, 6, and 5, respectively) and did

47 not attempt to place patterns of polymorphism in a phylogenetic context. Song et al. (2012)

48 examined the ITS2 region of 178 plant species via pyrosequencing, finding nearly ubiquitous

49 intragenomic variation, with most ITS2 copies within a genome represented by a few major

50 variants. Other studies have used intragenomic nrDNA polymorphisms to identify populations of

51 Arabidopsis (Simon et al., 2012) and infer intraspecific phylogenies of Saccharomyces (West et

52 al., 2014). Studies of intragenomic nrDNA polymorphism patterns across many species within the

53 same genus have not been performed in plants (but see Straub et al., 2012).

54 This study utilizes high throughput technology to survey many species and individuals in

55 the angiosperm genus Asclepias (Apocynaceae) in order to characterize levels of intragenomic

56 nrDNA polymorphism and place these within a phylogenetic context. The methods presented

57 here are expanded from those we have previously developed as part of the Milkweed Genome

58 Project (Straub et al., 2011, 2012), and generalized for use with a large number of taxa and any

59 high-copy locus, such as those that may be obtained from a genome-skimming or Hyb-Seq study

60 (Straub et al., 2012; Weitemier et al., 2014).

\section{METHODS}




\section{Sampling and sequencing}

63 One hundred twenty-five individuals representing 90 Asclepias species and subspecies

64 were sampled (Table 1) and sequencing libraries were produced as described in Straub et al.

65 (2012). Two individuals of putatively hybrid origin were included: A. albicans $\times$ subulata and $A$.

66 speciosa $\times$ syriaca. These individuals were collected from wild populations and identified as

67 hybrids through expression of intermediate morphological characteristics (M. Fishbein, unpubl.

68 data; see also Fishbein et al., 2011). Samples were multiplexed in approximately equimolar

69 ratios, with up to 21 individuals per lane, and sequenced with 80 bp single-end reads on an

70 Illumina GAIIx instrument (Illumina, San Diego California, USA). Asclepias subverticillata was

71 multiplexed in a lane with 32 samples and sequenced with $101 \mathrm{bp}$ paired-end reads on an

72 Illumina HiSeq 2000 instrument, with reads analyzed as though they were single-end. One

73 individual of $A$. syriaca was sequenced at higher coverage: this individual was sequenced in a

74 single lane on an Illumina GAIIx with 40 bp single-end reads (Straub et al., 2011). To allow more

75 efficient assembly downstream, read pools were filtered to remove plastid reads (using the

76 custom script sort_fastq_v1.pl modified to retain Ns; Knaus, 2010).

77 An A. syriaca haploid genome size estimate of $420 \mathrm{Mbp}$ and a nrDNA copy number

78 estimate of 960 were used for estimates of sequencing depth and for comparisons with other

79 organisms. These estimates are modified from Straub et al. (2011), where an incorrect estimate of

80 the average $A$. syriaca $2 \mathrm{C}$ value led to a haploid genome size estimate of $820 \mathrm{Mbp}$ and a nrDNA

81 copy number estimate of 1,845 . The current values are based on $2 \mathrm{C}$ estimates from Bai et al.

82 (2012) and Bainard et al. (2012).

\section{Polymorphism quantification}


84 The method for determining polymorphisms present among nrDNA copies within an

85 individual while retaining information about position homology across a group of distantly

86 related individuals included four general steps, detailed below: 1) A sequence was selected to

87 serve as a reference for the whole group. 2) A consensus sequence was obtained for each

88 individual taxon and aligned against the group reference, allowing tailored read-mapping for each

89 individual while associating positions along the individual consensus with their homologous

90 positions in the group reference. 3) Reads for each individual were mapped onto that individual's

91 consensus sequence. 4) At each position the reads differing from the individual consensus were

92 tallied.

93 1) Group reference

94 The nrDNA cistron of the high-coverage $A$. syriaca individual was previously assembled

95 (Straub et al., 2011; GenBank JF312046). The nontranscribed spacer and external transcribed

96 spacers from each end were removed due to the presence of internal repeats, and the more

97 conserved $18 \mathrm{~S}$ and $26 \mathrm{~S}$ subunits used as the boundaries of the alignment. The resulting reference

98 sequence contained $5839 \mathrm{bp}$.

99 2) Individual consensus sequences 
100 Read pools were examined prior to consensus assembly and reads that were exact

101 duplicates were reduced to a single representative, retaining the highest average quality score

102 (using the custom script fastq_collapse.py, available at https://github.com/listonlab). Sequences

103 for each individual were constructed via reference-guided assembly, with $A$. syriaca as the

104 reference, using Alignreads ver. 2.25 (Straub et al., 2011). Alignreads is a pipeline that includes

105 the short-read assembler YASRA (Ratan, 2009), utilities from the MUMmer ver. 3.0 suite

106 (Delcher et al., 2002; Kurtz et al., 2004), and custom scripts. Parameters were selected to ensure

107 high identity of reads mapping to the nrDNA reference (95\%), but allow the reconstructed

108 sequence to differ from the reference. In addition to assembling the individual consensus

109 sequence, Alignreads outputs a file associating each position in the group reference with those in

110 the individual consensus.

\section{3) Read mapping}

112 Prior to mapping reads from an individual onto its consensus, reads with an average

113 quality (Phred) score below 20 were removed, and bases in the remaining reads with a score

114 below 20 were converted to Ns using FASTX-Toolkit ver. 0.0.13 (Gordon, 2008). Read mapping

115 was performed with the program BWA ver. 0.5.7 (Li \& Durbin, 2009), and output files processed

116 with the SAMtools ver. 0.1.13 utilities (Li et al., 2009). 
117 Reads were mapped onto the consensus sequence using the default mapping parameters in

118 BWA. These allow up to 3 mismatches against the consensus in an $80 \mathrm{bp}$ read and 4 mismatches

119 in a $100 \mathrm{bp}$ read, with long insertions or deletions excluded. In order to test the effect of relaxed

120 mapping parameters on the abundance of polymorphisms detected, reads were mapped allowing

1214 or 5 mismatches in an 80 or 100 bp read, respectively (the $-\mathrm{n}$ flag in bwa aln set to 0.015 ).

122 The abundance of intragenomic indels was found by mapping reads using the default mismatch

123 parameters, but allowing indels up to $5 \mathrm{bp}$ long (bwa aln -e 4).

\section{4) Polymorphism counting}

125 A perl script was developed to tally the number of reads differing from the consensus at

126 each position (polymorphic_read_counter_bwaPileup.pl ver. 3.03b, available at

127 https://github.com/listonlab). For example, a base covered by 10 reads might have 7 reads with a

$128 \mathrm{G}$ in that position and 3 with a $\mathrm{C}$. In this case the consensus would have called a $\mathrm{G}$ at that

129 position, with $30 \%$ of the reads differing. See Supplemental File 1 for exact parameters and a

130 pipeline of commands used.

131 Positions with $2 \%$ or more of reads differing from the consensus base were considered

132 polymorphic. This cutoff is the same used by Straub et al. (2011) and comparable to that used by

133 Nguyen et al. (2011) under a similar quality-filtering scheme. The control PhiX lane of the higher

134 coverage $A$. syriaca individual was examined by Straub et al. (2011, Additional file 1 from that

135 study) and found to have an error rate much less than $2 \%$, indicating that the cutoff used here

136 may be somewhat conservative. In addition to counting positions that were polymorphic,

137 positions were recorded as "highly polymorphic" if $10 \%$ or more of the reads differed from the

138 consensus. 
139 In order to keep homologous bases aligned across individuals, only those positions that

140 were present in the $A$. syriaca (group) reference were kept in the analysis (i.e., insertions relative

141 to the reference were discarded). Note that deletions (relative to the reference) fixed within an

142 individual are also not considered because zero reads called a base at that position.

\section{RNA structure determination}

144 The secondary structure of each subunit and spacer region was predicted for the $A$.

145 syriaca reference from the minimum free energy structure found by the program RNAfold for the

146 18S, ITS1, and ITS2 regions and RNAcofold for the 5.8S+26S regions (Lorenz et al., 2011).

147 Program default model parameters were used $\left(37^{\circ} \mathrm{C}\right.$, unpaired bases can participate in up to one

148 dangling end). Positions along the cistron were then categorized as either paired (stems) or

149 unpaired (loops). Predicted structures are provided in Supplemental File 2.

\section{Polymorphisms within the cistron}


The effects of cistron position (subunit or spacer) and secondary structure position (stem

152 or loop) on the likelihood of a position being polymorphic or highly polymorphic were assessed

153 in two ways. Differences in the likelihood that at least one individual was polymorphic at a

154 position (e.g. positions coded as either polymorphic or invariant) were assessed via a two factor

155 multiple logistic regression, as implemented in R ver. 3.1.0 using the MASS ver. 7.3.33 package

156 (Venables \& Ripley, 2002; R Core Team, 2014). Differences in the abundance of polymorphic

157 individuals at a position were assessed using square-root transformed data with a two-way

158 ANOVA and type III sum of squares for unbalanced design, as implemented using the car ver.

159 2.0.20 package (Fox \& Weisberg, 2011). The ANOVA analysis is not reported for the highly

160 polymorphic individuals because the data diverge substantially from assumptions of a normal

161 distribution.

162 Phylogenetic context

163 A maximum likelihood estimate of phylogenetic relationships within Asclepias was

164 produced by Fishbein et al. (2011, Figure 2, TreeBase \#27576). This tree was pruned to match the

165 sampling in this study, and counts of polymorphic positions were recorded for each taxon. Taxa

166 sampled in this study, but not present in Fishbein et al. (2011), were omitted from further

167 analyses. Counts were averaged for taxa with multiple individuals in this study, but sampled only

168 once in Fishbein et al. (2011). Ancestral states for the number of polymorphic positions in the

169 rDNA cistron were reconstructed using squared-change parsimony in the Mesquite phylogenetic

170 suite ver. 2.75+ build 573 (Maddison \& Maddison, 2011; Maddison, Maddison \& Midford, 171 2011). 
173 two ways. In the first method, the total length of the tree (parsimony steps) in terms of changes in

174 number of polymorphic positions was compared to a distribution of tree lengths created by

17510,000 permutations of polymorphic positions across tips. In the second method, a likelihood

176 ratio test (LRT) was performed between models where character evolution followed a Brownian

177 motion model across the tree. In the first model, the parameter lambda (describing how well the

178 phylogeny correctly predicts the covariance among taxa for a trait) was found that maximized the

179 model's likelihood (Pagel, 1999). This was compared to the likelihood found when lambda was

180 held at zero, representing phylogenetic independence among species for that trait. Parsimony

181 permutations were performed in Mesquite (Maddison \& Maddison, 2011; Maddison, Maddison

$182 \&$ Midford, 2011), and likelihood ratio tests were performed in R with the phytools ver. 0.4.05

183 and ape ver. 3.1.2 packages (Paradis, Claude \& Strimmer, 2004; Revell, 2012; R Core Team,

184 2014). 
186 significantly high or low relative to the rest of the phylogeny, polymorphism rates were simulated

187 along the tree and the true polymorphism counts compared to the distribution of simulated counts

188 (Garland et al., 1993). Two tips in the tree separated by zero branch length (A. asperula ssp.

189 asperula and ssp. capricornu) were collapsed, and the average of the polymorphism counts for

190 the four sampled individuals of the species used for the new tip. A model of trait evolution under

191 Brownian motion, using the lambda parameter estimated from the LRT above, was found from

19210,000 random starting points using the fitContinuous function from the geiger ver. 2.0.3 $\mathrm{R}$

193 package (Harmon et al., 2008). This model was used to simulate polymorphism counts across the

194 phylogeny 10,000 times, with lower and upper bounds of 0 and infinity, respectively, using the

195 fastBM function in phytools ver. 0.4.31 (Revell, 2012). For each node, the ancestral state was

196 estimated for the true data and the simulated data using squared change parsimony as

197 implemented in Mesquite (Maddison \& Maddison, 2011; Maddison, Maddison \& Midford, 198 2011).

\section{RESULTS}

201 Sequence Read Archive PRJNA261980). Despite high overall coverage of the nrDNA region, not

202 all positions of the cistron were assembled for all individuals; therefore results for polymorphic

203 positions are presented both as counts and as percentages of sequenced bases. The $A$. syriaca

204 reference had total genome coverage of $\sim 0.8 x$ (Sequence Read Archive SRP005621). 

sequences for the nrDNA cistrons of other samples ranged from $5815-5865 \mathrm{bp}$, with over half of samples having lengths between 5836 and 5842 bp. Relative to $A$. syriaca, 87 samples include at least one inserted position in their consensus sequence, and 117 samples have at least one deleted position. However, because in general more positions were inserted than deleted, 71 samples have lengths greater than 5839, and 41 samples have shorter lengths (Fig. S1).

\section{Intragenomic polymorphism}

All individuals were polymorphic at several positions homologous with the A. syriaca

213 reference (Table 1). Number of polymorphic positions ranged from 23 (A. verticillata, $0.41 \%$ of

214 sequenced bases) to 882 (A. solanoana, 15.13\%), with a mean of 333 (5.77\%, Fig. 1). A very

215 high percentage (91\%) of positions in the A. syriaca reference were polymorphic in at least one 216 individual (Fig. 2A).

217 Positions were significantly more likely to be polymorphic if they were in a spacer region 218 (ITS1, ITS2; Fig. 2A) or stem (Fig. 3A). This is true both when considering the number of

219 individuals polymorphic at a position (Table 2), and whether any sample was polymorphic at that 220 position (Table 3A). 
222 (A. boliviensis, 1.91\%) with a mean of 28 (0.50\%). Positions highly polymorphic in more than 10

223 individuals were found in the 18S, ITS1, ITS2, and 26S regions (Fig. 2B). The most polymorphic

224 position was 4172 (using the $A$. syriaca reference), in the 26S region, which was highly

225 polymorphic in 29 individuals. Highly polymorphic positions were dramatically less frequent in

226 the subunit regions $(18 \mathrm{~S}=19 \%, 5.8 \mathrm{~S}=26 \%, 26 \mathrm{~S}=31 \%)$ than in the spacer regions (ITS $1=61 \%$,

227 ITS2=57\%; Table 3B, Fig. 2B). Positions in secondary structure stems were moderately more

228 likely to be highly polymorphic in at least one individual than loop positions (Table 3B, Fig. 3B).

\section{Relaxed Read Mapping}

Allowing more mismatches when mapping reads to their consensus nrDNA sequence

231 increased the polymorphic sites counted within individuals by an average of 15.5\% (Fig. S2).

232 Two samples had no change in their polymorphism abundance, and two had a decrease (i.e.,

233 newly mapped reads at a previously polymorphic position matched the consensus, thereby

234 dropping the polymorphic reads below $2 \%$ ). The increase in polymorphism abundance under

235 relaxed read mapping may indicate that the standard read mapping parameters are too

236 conservative and that some truly polymorphic sites are excluded. However, because standard read

237 mapping is more likely to exclude reads containing sequencing errors, and because there is a

238 strong linear correlation $\left(R^{2}=0.97\right)$ between polymorphism abundance under the two mapping

239 schemes, remaining analyses will only consider results from the standard read mapping. 
241 reads were allowed to contain insertions or deletions of up to $5 \mathrm{bp}$ relative to the individual

242 consensus sequence. Eight individuals exhibited no polymorphic indels, including a sample of $A$.

243 tuberosa ssp. rolfsii (Lynch 12526 [OKLA]). However, a sample of A. tuberosa ssp. interior

244 (Fishbein 2816 [OKLA]) contained the most polymorphic indels at 51. Intragenomic indel

245 abundance was positively correlated with SNP abundance $\left(R^{2}=0.35\right.$, Fig. S3). Due to the

246 generally low level of intragenomic indel polymorphisms ( $78 \%$ of samples contained 10 or

247 fewer) remaining analyses only consider results from intragenomic polymorphic SNPs.

248 Polymorphic indels and SNP counts under relaxed mapping for each sample are provided in

249 Supplemental File 3.

250 Phylogenetic Signal

251 The number of polymorphic base pair positions exhibited strong phylogenetic signal

252 across Asclepias under both the permutation test $(P<0.0012)$ and the likelihood ratio test

253 (estimated lambda $=0.51, P=0.0067$; Table 4; Fig. 4). This signal remained even after the ITS

254 regions were removed from the dataset (permutation test $P<0.0200$, lambda $=0.45$, LRT

$255 P=0.0112$ ). Highly polymorphic base pair abundance, however, was not significantly influenced

256 by phylogenetic history (Table 4; Fig. 5), even when considering only the subunit regions. 
Of the 53 resolved clades in the phylogeny, none showed polymorphism values more

258

259

260

261

262

263

264

265

266

267

268

269

270

271

272

273

274

275

276

277

278

extreme than expected under a Brownian motion model after correcting for multiple comparisons.

The most extreme clade was that formed by A. hypoleuca and A. otarioides, which had an ancestral number of polymorphic positions exceeded by 79 of the 10,000 simulations (when excluding the spacer regions this node was exceeded by 60 simulations). The following most extreme nodes were those ancestral to $A$. rosea and A. lemmonii with more polymorphic positions than all but 130 (79) simulations, and ancestral to A. boliviensis and A. mellodora with more polymorphic positions than all but 246 (150) simulations. Under a Bonferroni correction a clade would require 9 or fewer simulations more extreme than the observed value $(\alpha=0.05)$ to reject a hypothesis of no divergence from Brownian motion.

Despite the strong phylogenetic signal of polymorphism abundance across Asclepias, counts among samples within species (for those species with multiple samples) exhibited variability. Some samples of the same species had very similar polymorphism counts (e.g., the two A. jaliscana individuals contained 140 and 165 intragenomic polymorphisms), while others differed dramatically (e.g., A. macrosperma individuals contained 76 and 391).

\section{Identification of Mixed Ancestry}

The number of polymorphic sites for hybrid individuals, 299 for $A$. albicans $\times$ subulata and 161 for $A$. speciosa $\times$ syriaca, are less than the mean number of 333 polymorphic sites; and the number of highly polymorphic sites, 12 and 37, are less than or greater than the mean of 28. Of those positions that are highly polymorphic, 4 of 37 in $A$. speciosa $\times$ syriaca have a minor allele frequency of 0.3 or higher, while none of the positions in A. albicans $\times$ subulata have a minor allele frequency above 0.2 . 
279 DISCUSSION 
Absolute counts of intragenomic polymorphisms among the copies of nrDNA in

281

282

283

284

285

286

287

288

289

290

291

292

293

294

295

296

297

298

299

300

301

302

303

Asclepias (mean=333 positions) were found to be much higher than levels reported for nematodes (<250; Bik et al., 2013), fungi (3-37; Ganley \& Kobayashi, 2007), and Drosophila (318; Stage \& Eickbush, 2007) when including all polymorphic positions. When considering only positions that are highly polymorphic, Asclepias exhibits slightly higher rates (mean=28.4 positions) than fungi and Drosophila, but much lower rates than nematodes. However, these comparisons may be misleading: First, the number of nrDNA copies varies greatly between these taxa, estimated to range from about 50-180 in the fungal species, 200-250 in Drosophila melanogaster, 56-323 in the nematodes, and about 960 in Asclepias (Ganley \& Kobayashi, 2007; Stage \& Eickbush, 2007; Straub et al., 2011; Bik et al., 2013). Second, polymorphic base pair counts are confounded by differing criteria for scoring polymorphism (i.e., methods for excluding sequencing errors). The levels listed for the fungal species include both "high-confidence" and "low-confidence" polymorphisms, based primarily on sequence quality (Ganley \& Kobayashi, 2007). The levels listed for Drosophila are polymorphisms present in $\geq 3 \%$ of loci (Stage \& Eickbush, 2007). Bik et al. (2013) tallied read counts using a method similar to the method presented here, but called positions polymorphic when the count of differing reads exceeded what would be expected for a single copy locus. Third, sequencing depths of the fungal and Drosophila studies were much lower than those used here and with the nematodes (Ganley \& Kobayashi, 2007; Stage \& Eickbush, 2007; Bik et al., 2013). Nevertheless, given that Asclepias has absolute counts of polymorphic positions at least 33\% higher than the other organisms studied, and that the sequencing depth was nearly two orders of magnitude greater in the nematodes than in Asclepias (6.3-10x per nrDNA copy in nematodes, vs. $\sim 0.1 \mathrm{x}$ in Asclepias; Bik et al., 2013), it is likely that Asclepias harbors greater rates of intragenomic polymorphism within the nrDNA cistron than the organisms studied to date. 
Polymorphism patterns across the nrDNA cistron regions (18S, 5.8S, 26S; Fig. 2). However, positions with low polymorphism frequencies are

307 distributed much more evenly across the nrDNA cistron (Fig. 2A) than highly polymorphic

308 positions, which show strong differentiation between the subunit and spacer regions (Fig. 2B).

309 The lower frequency of highly polymorphic positions within the subunit regions suggests that

310 these regions are under selection to remain homogenous within individual genomes. The lower

311 difference in low polymorphism frequency between subunit and spacer regions suggests that this

312 selection pressure is positively correlated with the proportion of nrDNA copies that differ from

313 the majority. These findings contrast with those reported for nematodes (Bik et al., 2013), where

314 the subunit regions had much higher levels of polymorphism abundance than the spacer regions. 
315 Positions in stem regions were more likely to be polymorphic than loop positions (Fig. 3).

316 This was strongly significant for all polymorphic positions (Tables 2, 3A) and moderately

317 significant for highly polymorphic positions (Table 3B). This would seem to contradict the

318 hypothesis that stem sites in general should be more highly conserved in order to maintain a

319 functional RNA secondary structure. Indeed, this finding agrees with those from Rhetsky (1995),

320 who not only found that trees estimated from stem regions contained longer branch lengths than

321 those from loop regions, but that those stem sites least likely to affect secondary structure tended

322 to be less conserved. Loop sites, on the other hand, contain a large proportion of the sites critical

323 to ribosomal function (Rzhetsky, 1995), and may be under stronger stabilizing selection than stem

324 sites.

325 Among the subunit regions, the 26S region harbored the highest frequency of highly

326 polymorphic positions. This agrees with Stage \& Eickbush (2007) who showed the Drosophila

$32728 \mathrm{~S}$ region to have a higher mutation rate than the other subunit regions. However, in that study

328 the 28 S region also had a lower frequency of polymorphic base pairs. Stage \& Eickbush (2007)

329 hypothesize that this is due to the action of two retrotransposable elements found in many

330 Drosophila 28S copies, with instances of aborted insertions causing the cell to repair the region

331 using a nearby template and thereby homogenize the copies. They predict that levels of

332 polymorphism will be higher in the $28 \mathrm{~S}$ region of organisms lacking the retrotransposable

333 elements, as seen here in the homologous angiosperm 26S region. 
335 expansion regions of the RNA gene (less conserved regions that tend to incorporate sequence

336 insertions without affecting functionality; Clark et al., 1984). This is strongly implied by the

337 recovery of clusters of highly polymorphic sites near $A$. syriaca positions 4440 and 5020, which

338 are directly within the $26 \mathrm{~S}$ expansion regions seven and eight, respectively (Kolosha \& Fodor,

339 1990; Fig. 1). This agrees with results found in Drosophila (Stage \& Eickbush, 2007). However,

340 this may not be true for all highly polymorphic sites, as the high peak at position 4172 is not

341 within an expansion region.

\section{Phylogenetic context}

343 Mapping the number of polymorphic positions onto the phylogeny of Asclepias

344 demonstrates strong and significant phylogenetic signal when counting all polymorphisms (Fig.

345 4), but this signal is not significant when only counting highly polymorphic positions (Fig. 5).

346 While this study demonstrates phylogenetic signal in polymorphism abundance, it remains

347 unknown whether abundance within a lineage is influenced by selection or purely neutral causes.

348 Different demographic histories across clades could create this effect via neutral causes, while

349 selection against organisms that retain too many variant nrDNA copies could be variable across

350 the genus. Polymorphisms present in a high proportion of nrDNA copies may be uniformly

351 selected against, while low polymorphism sites are tolerated at varying levels. This could explain

352 the lack of phylogenetic signal at the highly polymorphic sites, and its presence when including

353 all polymorphic sites. 
355 previously cautioned, it cannot be assumed that all copies of nrDNA are identical within a

356 genome. This is especially true for the spacer regions, but also for the subunit regions (Álvarez \&

357 Wendel, 2003). The discovery of phylogenetic signal in intragenomic polymorphism abundance

358 demonstrates that those positions likely to lead to ambiguities are not distributed evenly across

359 the phylogeny (Fig. 4). In addition to topology, variable polymorphism rates among lineages may

360 affect the estimation of branch lengths on a tree. This may become especially problematic when

361 nrDNA is used to date phylogenies. Recently developed methods of phylogenetic inference

362 incorporating information about polymorphic positions may be able to alleviate difficulties in tree

363 building caused by uneven levels of polymorphism abundance (Potts, Hedderson \& Grimm, 364 2014).

\section{Identification of mixed ancestry}


367 of hybrid offspring between parents with differing nrDNA sequences (Zimmer, Jupe \& Walbot,

368 1988), and may be able to provide an estimate of the number of generations since hybridization.

369 This is especially true for early generation hybrids, as nrDNA homogenization can occur in a

370 small number of generations (Kovarik et al., 2005), and mosaic Saccharomyces genomes have

371 been identified based on intragenomic polymorphism abundance (West et al., 2014). Neither of

372 the polymorphism profiles for the two wild-collected putative hybrid individuals in this study

373 strongly indicate that they are early generation hybrids. This is in contrast to evidence from

374 nuclear gene sequences that show heterozygosity consistent with inheritance of divergent alleles

375 from the putative parents in the A. albicans $\times$ A. subulata hybrid (B. Haack and M. Fishbein,

376 unpupl. data). Detection of mixed ancestry may be hampered in this case by a lack of fixed

377 differences between parental haplotypes. Consensus sequences for the A. albicans and $A$.

378 subulata individuals in this study show no fixed differences, while one difference is found

379 between the $A$. syriaca and $A$. speciosa consensus sequences. Unexpectedly, this position is

380 monomorphic in the hybrid, while the positions with minor allele frequencies $>0.3$ are in

381 positions not shown to differ between $A$. syriaca and $A$. speciosa. This likely indicates ancestry

382 from an unsampled nrDNA haplotype. 
384 indicate the presence of cryptic diversity. Differing demographic histories between populations

385 within a species may lead to individuals from those populations possessing different levels of

386 intragenomic polymorphisms. As with the interspecific hybrids discussed above, early generation

387 hybrids between populations within a species could also possess inflated levels of intragenomic 388 polymorphisms.

\section{Conclusions}

Nuclear ribosomal DNA copies within individuals of Asclepias are not identical, with

391 intragenomic polymorphisms present at a higher rate than reported for other organisms.

392 Polymorphism frequencies across the genus vary by more than an order of magnitude and

393 demonstrate strong phylogenetic signal. Stem positions of ribosomal subunits are more likely to

394 be polymorphic than loop positions. Distribution of polymorphic sites across the nrDNA cistron

395 are consistent with strong selection on nrDNA subunits, with polymorphic sites being more

396 frequent in the spacer regions, and this difference being amplified for sites that are highly

397 polymorphic. These results reinforce the need for caution when using nrDNA for phylogenetic

398 inference, especially when using the spacer regions or for applications requiring the precise

399 estimates of branch lengths or divergence times.

\section{ACKNOWLEDGMENTS}


The authors thank Richard Cronn for helpful comments and suggestions during the

402 execution of this work. Expert laboratory assistance from Shakuntala Fathepure, Ben Haack,

403 LaRinda Holland, Angela McDonnell, Laura Mealy, Nicole Nasholm, Matthew Parks, and

404 Lauren Ziemian was a crucial contribution to this research. Kind thanks go to James Riser, who

405 generously shared DNA extractions. Computer infrastructure was provided by the Center for

406 Genome Research and Biocomputing at Oregon State University. Processing of sequences for the

407 Sequence Read Archive was performed by Sanjuro Jogdeo.

\section{LITERATURE CITED}

Álvarez I, Wendel JF. 2003. Ribosomal ITS sequences and plant phylogenetic inference. Plant Molecular Evolution 29:417-434.

Bai C, Alverson WS, Follansbee A, Waller DM. 2012. New reports of nuclear DNA content for 407 vascular plant taxa from the United States. Annals of Botany 110:1623-1629.

Bainard JD, Bainard LD, Henry TA, Fazekas AJ, Newmaster SG. 2012. A multivariate analysis of variation in genome size and endoreduplication in angiosperms reveals strong phylogenetic signal and association with phenotypic traits. New Phytologist 196:1240-1250.

Baldwin BG. 1992. Phylogenetic utility of the internal transcribed spacers of nuclear ribosomal DNA in plants: An example from the Compositae. Molecular Phylogenetics and Evolution 1:3-16.

Baldwin BG, Sanderson MJ, Porter JM, Wojciechowski MF, Campbell CS, Donoghue MJ. 1995. The ITS region of nuclear ribosomal DNA: A valuable source of evidence on angiosperm phylogeny. Annals of the Missouri Botanical Garden 82:247-277.

Bik HM, Fournier D, Sung W, Bergeron RD, Thomas WK. 2013. Intra-genomic variation in the ribosomal repeats of nematodes. PLOS ONE 8:e78230.

Buckler ES, Ippolito A, Holtsford TP. 1997. The Evolution of Ribosomal DNA Divergent Paralogues and Phylogenetic Implications. Genetics 145:821-832. 
Clark CG, Tague BW, Ware VC, Gerbi SA. 1984. Xenopus laevis 28S ribosomal RNA: A secondary structure model and its evolutionary and functional implications. Nucleic Acids Research $12: 6197-6220$.

Delcher AL, Phillippy A, Carlton J, Salzberg SL. 2002. Fast algorithms for large-scale genome alignment and comparison. Nucleic Acids Research 30:2478 -2483.

Fishbein M, Chuba D, Ellison C, Mason-Gamer RJ, Lynch SP. 2011. Phylogenetic relationships of Asclepias (Apocynaceae) inferred from non-coding chloroplast DNA sequences. Systematic Botany 36:1008-1023.

Fox J, Weisberg S. 2011. An R Companion to Applied Regression. Thousand Oaks, CA: Sage.

Ganley ARD, Kobayashi T. 2007. Highly efficient concerted evolution in the ribosomal DNA repeats: Total rDNA repeat variation revealed by whole-genome shotgun sequence data. Genome Research $17: 184-191$.

Garland T, Dickerman AW, Janis CM, Jones JA. 1993. Phylogenetic analysis of covariance by computer simulation. Systematic Biology 42:265-292.

Gernandt DS, Liston A. 1999. Internal transcribed spacer region evolution in Larix and Pseudotsuga (Pinaceae). American Journal of Botany 86:711-723.

Gordon A. 2008. FASTX toolkit.

Hamby RK, Zimmer EA. 1988. Ribosomal RNA sequences for inferring phylogeny within the grass family (Poaceae). Plant Systematics and Evolution 160:29-37.

Harmon LJ, Weir JT, Brock CD, Glor RE, Challenger W. 2008. GEIGER: Investigating evolutionary radiations. Bioinformatics 24:129-131.

Hillis DM, Dixon MT. 1991. Ribosomal DNA: Molecular evolution and phylogenetic inference. Quarterly Review of Biology 66:411-453.

Karvonen P, Savolainen O. 1993. Variation and inheritance of ribosomal DNA in Pinus sylvestris L. (Scots pine). Heredity 71:614-622.

Knaus B. 2010. Short read toolbox.

Kolosha VO, Fodor I. 1990. Nucleotide sequence of Citrus limon 26S ribosomal-RNA gene and secondary structure model of its RNA. Plant Molecular Biology 14:147-161. 
Kovarik A, Pires JC, Leitch AR, Lim KY, Sherwood AM, Matyasek R, Rocca J, Soltis DE, Soltis PS. 2005. Rapid concerted evolution of nuclear ribosomal DNA in two Tragopogon allopolyploids of recent and recurrent origin. Genetics 169:931-944.

Kurtz S, Phillippy A, Delcher AL, Smoot M, Shumway M, Antonescu C, Salzberg SL. 2004. Versatile and open software for comparing large genomes. Genome Biol 5:R12.

Li H, Durbin R. 2009. Fast and accurate short read alignment with Burrows-Wheeler transform. Bioinformatics 25:1754-1760.

Li H, Handsaker B, Wysoker A, Fennell T, Ruan J, Homer N, Marth G, Abecasis G, Durbin R, 1000 Genome Project Data Processing Subgroup. 2009. The Sequence Alignment/Map format and SAMtools. Bioinformatics 25:2078 -2079.

Lorenz R, Bernhart S, Honer zu Siederdissen C, Tafer H, Flamm C, Stadler P, Hofacker I. 2011. ViennaRNA Package 2.0. Algorithms for Molecular Biology 6:26.

Maddison WP, Maddison DR. 2011. Mesquite: a modular system for evolutionary analysis.

Maddison WP, Maddison DR, Midford PE. 2011. Tree Farm package for Mesquite.

Nguyen P, Ma J, Pei D, Obert C, Cheng C, Geiger T. 2011. Identification of errors introduced during high throughput sequencing of the T cell receptor repertoire. BMC Genomics 12:106.

Pagel M. 1999. Inferring the historical patterns of biological evolution. Nature 401:877-884.

Paradis E, Claude J, Strimmer K. 2004. APE: Analyses of phylogenetics and evolution in R language. Bioinformatics 20:289-290.

Potts AJ, Hedderson TA, Grimm GW. 2014. Constructing phylogenies in the presence of intra-individual site polymorphisms (2ISPs) with a focus on the nuclear ribosomal cistron. Systematic Biology 63:1-16.

Ratan A. 2009. Assembly algorithms for next-generation sequence data. PhD Dissertation Thesis. University Park, Pennsylvania, USA: Pennsylvania State University.

R Core Team. 2014. R: A language and environment for statistical computing. Vienna, Austria: $\mathrm{R}$ Foundation for Statistical Computing.

Revell LJ. 2012. phytools: An R package for phylogenetic comparative biology (and other things). Methods in Ecology and Evolution 3:217-223. 
Rzhetsky A. 1995. Estimating substitution rates in ribosomal RNA genes. Genetics 141:771-783.

Schlötterer C, Tautz D. 1994. Chromosomal homogeneity of Drosophila ribosomal DNA arrays suggests intrachromosomal exchanges drive concerted evolution. Current Biology 4:777-783.

Simon UK, Trajanoski S, Kroneis T, Sedlmayr P, Guelly C, Guttenberger H. 2012. Accession-specific haplotypes of the internal transcribed spacer region in Arabidopsis thaliana-A means for barcoding populations. Molecular Biology and Evolution 29:2231-2239.

Song J, Shi L, Li D, Sun Y, Niu Y, Chen Z, Luo H, Pang X, Sun Z, Liu C et al. 2012. Extensive Pyrosequencing Reveals Frequent Intra-Genomic Variations of Internal Transcribed Spacer Regions of Nuclear Ribosomal DNA. PLoS ONE 7:e43971.

Stage DE, Eickbush TH. 2007. Sequence variation within the rRNA gene loci of 12 Drosophila species. Genome Research 17:1888-1897.

Straub S, Fishbein M, Livshultz T, Foster Z, Parks M, Weitemier K, Cronn R, Liston A. 2011. Building a model: Developing genomic resources for common milkweed (Asclepias syriaca) with low coverage genome sequencing. BMC Genomics 12:211.

Straub SCK, Parks M, Weitemier K, Fishbein M, Cronn RC, Liston A. 2012. Navigating the tip of the genomic iceberg: Next-generation sequencing for plant systematics. American Journal of Botany 99:349-364.

Venables WN, Ripley BD. 2002. Modern Applied Statistics with S. New York: Springer.

Weitemier K, Straub SCK, Cronn RC, Fishbein M, Schmick1 R, McDonnell A, Liston A. 2014. Hyb-Seq: Combining target enrichment and genome skimming for plant phylogenomics. Applications in Plant Sciences: 1400042.

West C, James SA, Davey RP, Dicks J, Roberts IN. 2014. Ribosomal DNA sequence heterogeneity reflects intraspecies phylogenies and predicts genome structure in two contrasting yeast species. Systematic Biology 63:543-554.

Zimmer EA, Jupe ER, Walbot V. 1988. Ribosomal gene structure, variation and inheritance in maize and its ancestors. Genetics 120:1125-1136. 
Table $\mathbf{1}_{\text {(on next page) }}$

Polymorphic site abundance in Asclepias.

Polymorphic site abundance in Asclepias taxa. Voucher: Collector, collection \#, [herbarium]. Poly \#: Number of polymorphic positions. Poly \%: Percentage of assembled positions that are polymorphic. High \#, High \%: Number and percentage of highly polymorphic positions. SRA: NCBI Sequence Read Archive accession number. 


\begin{tabular}{|c|c|c|c|c|c|c|}
\hline Asclepias taxon & Voucher & Poly \# & Poly \% & High \# 1 & High \% & SRA \\
\hline A. albicans S. Watson & Fishbein 3146 [WS] & 174 & 3.12 & 16 & 0.29 & SRS721451 \\
\hline A. albicans & Fishbein 6463 [OKLA] & 273 & 4.7 & 11 & 0.19 & SRS721452 \\
\hline A. alticola E. Fourn. & Steinmann 5243 [IEB] & 668 & 11.45 & 31 & 0.53 & SRS721453 \\
\hline A. amplexicaulis Sm. & Lynch 12652 [OKLA] & 248 & 4.25 & 25 & 0.43 & SRS721454 \\
\hline A. angustifolia Schweigg. & Reina 2004-1315 [ARIZ] & 55 & 1.04 & 36 & 0.68 & SRS721455 \\
\hline A. angustifolia & Reina 2008-203 [OKLA] & 169 & 2.99 & 26 & 0.46 & SRS721456 \\
\hline A. arenaria Torr. & Lynch 11495 [OKLA] & 174 & 2.98 & 2 & 0.03 & SRS721457 \\
\hline $\begin{array}{l}\text { A. asperula (Decne.) } \\
\text { Woodson ssp. asperula }\end{array}$ & Lynch 12037 [OKLA] & 342 & 5.87 & 7 & 0.12 & SRS721458 \\
\hline A. asperula ssp. asperula & Fishbein 6536 [OKLA] & 391 & 6.73 & 24 & 0.41 & SRS721459 \\
\hline $\begin{array}{l}\text { A. asperula ssp. capricornu } \\
\text { (Woodson) Woodson }\end{array}$ & Lynch 13314 [OKLA] & 474 & 8.15 & 38 & 0.65 & SRS721460 \\
\hline A. asperula ssp. capricornu & Fishbein 6486 [OKLA] & 347 & 5.95 & 6 & 0.1 & SRS721461 \\
\hline A. atroviolacea Woodson & Fishbein 3612 [ARIZ] & 451 & 7.73 & 26 & 0.45 & SRS721462 \\
\hline A. auriculata Kunth & Lynch 1694 [OKLA] & 513 & 8.85 & 33 & 0.57 & SRS721463 \\
\hline A. auriculata & Fishbein 5833 [OKLA] & 378 & 6.54 & 39 & 0.68 & SRS721464 \\
\hline A. boliviensis E. Fourn. & Fishbein 6072 [OKLA] & 875 & 15.08 & 111 & 1.91 & SRS721465 \\
\hline $\begin{array}{l}\text { A. brachystephana Engelm. } \\
\text { ex Torr. }\end{array}$ & Lynch 10642 [OKLA] & 309 & 5.32 & 22 & 0.38 & SRS721466 \\
\hline A. californica Greene & Lynch 10779 [OKLA] & 472 & 8.09 & 24 & 0.41 & SRS721467 \\
\hline A. aff. candida Vell. & Fishbein 6347 [OKLA] & 245 & 4.2 & 14 & 0.24 & SRS721448 \\
\hline A. cinerea Walter & Fishbein 4793 [OKLA] & 297 & 5.1 & 27 & 0.46 & SRS721468 \\
\hline $\begin{array}{l}\text { A. circinalis (Decne.) } \\
\text { Woodson }\end{array}$ & Webster 17186 [OKLA] & 464 & 7.95 & 59 & 1.01 & SRS721469 \\
\hline $\begin{array}{l}\text { A. connivens Baldwin ex } \\
\text { Elliott }\end{array}$ & Lynch 12336 [OKLA] & 394 & 6.75 & 16 & 0.27 & SRS721470 \\
\hline A. cordifolia (Benth.) Jeps. & Lynch 10942 [OKLA] & 344 & 5.96 & 30 & 0.52 & SRS721471 \\
\hline A. cordifolia & Fishbein 5772 [OKLA] & 308 & 5.35 & 13 & 0.23 & SRS721472 \\
\hline A. coulteri A. Gray & Ventura \& Lopez 7986 [TEX] & 471 & 8.09 & 27 & 0.46 & SRS721473 \\
\hline $\begin{array}{l}\text { A. cryptoceras S. Watson } \\
\text { ssp. cryptoceras }\end{array}$ & Fishbein 6504 [OKLA] & 230 & 4 & 35 & 0.61 & SRS721474 \\
\hline $\begin{array}{l}\text { A. cryptoceras ssp. davisii } \\
\text { (Woodson) Woodson }\end{array}$ & Fishbein 5723 [OKLA] & 350 & 6 & 13 & 0.22 & SRS721475 \\
\hline A. curassavica L. & Zuloaga \& Morrone 7087 [OKLA] & 258 & 4.42 & 24 & 0.41 & SRS721476 \\
\hline A. cutleri Woodson & Fishbein 6511 [OKLA] & 167 & 2.9 & 18 & 0.31 & SRS721477 \\
\hline A. cutleri & Fishbein 6500 [OKLA] & 157 & 2.69 & 8 & 0.14 & SRS721478 \\
\hline $\begin{array}{l}\text { A. emoryi (Greene) Vail ex } \\
\text { Small }\end{array}$ & Carr 12032 [TEX] & 124 & 2.29 & 44 & 0.81 & SRS721479 \\
\hline A. engelmanniana Woodson & Lynch 11224 [OKLA] & 141 & 2.54 & 33 & 0.59 & SRS721480 \\
\hline A. engelmanniana & Lynch 11029 [OKLA] & 192 & 3.3 & 7 & 0.12 & SRS721482 \\
\hline A. eriocarpa Benth. & Lynch 10923 [OKLA] & 610 & 10.49 & 32 & 0.55 & SRS721483 \\
\hline A. eriocarpa & Lynch 10799 [OKLA] & 492 & 8.43 & 17 & 0.29 & SRS721481 \\
\hline A. feayi Chapm. ex A. Gray & Fishbein 5586 [OKLA] & 329 & 5.71 & 42 & 0.73 & SRS721484 \\
\hline A. fournieri Woodson & Fishbein 3660 [ARIZ] & 556 & 9.58 & 47 & 0.81 & SRS721530 \\
\hline
\end{tabular}




\begin{tabular}{|c|c|c|c|c|c|c|}
\hline A. fournieri & Lynch 1655 [OKLA] & 711 & 12.25 & 49 & 0.84 & SRS721485 \\
\hline A. glaucescens Kunth & Lynch 14142 [OKLA] & 190 & 3.33 & 19 & 0.33 & SRS721486 \\
\hline A. glaucescens & Lynch 1623 [OKLA] & 90 & 1.69 & 85 & 1.6 & SRS721487 \\
\hline A. glaucescens & Fishbein 5097 [OKLA] & 215 & 3.72 & 18 & 0.31 & SRS721488 \\
\hline A. sp. nov. aff. glaucescens & Fishbein 3671 [ARIZ] & 225 & 3.87 & 25 & 0.43 & SRS721490 \\
\hline A. hallii A. Gray & Lynch 11299 [OKLA] & 600 & 10.36 & 54 & 0.93 & SRS721449 \\
\hline A. humistrata Walter & Fishbein 5596 [OKLA] & 331 & 5.67 & 13 & 0.22 & SRS721489 \\
\hline $\begin{array}{l}\text { A. hypoleuca (A. Gray) } \\
\text { Woodson }\end{array}$ & Lynch 11374 [OKLA] & 670 & 11.51 & 44 & 0.76 & SRS721491 \\
\hline A. incarnata L. & Lynch 12567 [OKLA] & 434 & 7.45 & 28 & 0.48 & SRS721492 \\
\hline $\begin{array}{l}\text { A. involucrata Engelm. ex } \\
\text { Torr. }\end{array}$ & Lynch 12050 [OKLA] & 326 & 5.65 & 35 & 0.61 & SRS721494 \\
\hline A. involucrata & Fishbein 6531 [OKLA] & 217 & 3.72 & 13 & 0.22 & SRS721493 \\
\hline A. jaliscana B.L. Rob. & Fishbein 2493 [ARIZ] & 140 & 2.97 & 74 & 1.57 & SRS721495 \\
\hline A. jaliscana & Fishbein 3657 [WS] & 165 & 3 & 65 & 1.18 & SRS721496 \\
\hline $\begin{array}{l}\text { A. jorgeana Fishbein \& S.P. } \\
\text { Lynch }\end{array}$ & Vásquez \& Alvarez 4905 [IEB] & 160 & 2.76 & 12 & 0.21 & SRS721497 \\
\hline A. lanceolata Walter & Fishbein 5605 [MISSA] & 249 & 4.27 & 8 & 0.14 & SRS721498 \\
\hline A. lanuginosa Nutt. & Lynch 12661 [OKLA] & 343 & 5.92 & 11 & 0.19 & SRS721499 \\
\hline A. latifolia (Torr.) Raf. & Lynch 11018 [OKLA] & 236 & 4.05 & 11 & 0.19 & SRS721500 \\
\hline A. lemmonii A. Gray & Lynch 11453 [OKLA] & 620 & 10.7 & 23 & 0.4 & SRS721501 \\
\hline A. leptopus I.M. Johnst. & Fishbein 6263 [OKLA] & 282 & 4.84 & 9 & 0.15 & SRS721502 \\
\hline A. longifolia Michx. & Lynch 12447 [OKLA] & 427 & 7.34 & 24 & 0.41 & SRS721503 \\
\hline A. lynchiana Fishbein & Venable \& Becerra s.n. [ARIZ] & 129 & 2.39 & 31 & 0.57 & SRS721504 \\
\hline A. macrosperma Eastw. & Gierisch 4191 [ARIZ] & 76 & 1.42 & 30 & 0.56 & SRS721505 \\
\hline A. macrosperma & Fishbein 6518 [OKLA] & 391 & 6.72 & 21 & 0.36 & SRS721506 \\
\hline A. macrotis Torr. & Lynch 11260 [OKLA] & 364 & 6.27 & 11 & 0.19 & SRS721507 \\
\hline A. macrotis & Lynch 11263 [OKLA] & 260 & 4.46 & 5 & 0.09 & SRS721508 \\
\hline A. masonii Woodson & Fishbein 3101 [OKLA] & 151 & 2.59 & 7 & 0.12 & SRS721509 \\
\hline A. meadii Torr. ex A. Gray & Freeman 9106 [KANU] & 208 & 3.62 & 20 & 0.35 & SRS721510 \\
\hline A. mellodora A. St.-Hil. & Zuloaga \& Morrone 7168 [OKLA] & 377 & 6.47 & 18 & 0.31 & SRS721511 \\
\hline A. mexicana Cav. & Fishbein 3009 [ARIZ] & 186 & 3.22 & 18 & 0.31 & SRS721513 \\
\hline A. michauxii Decne. & Lynch 12316 [OKLA] & 458 & 7.87 & 39 & 0.67 & SRS721512 \\
\hline A. notha W.D. Stevens & Lynch 14113 [OKLA] & 375 & 6.45 & 44 & 0.76 & SRS721515 \\
\hline A. notha & Fishbein 5389 [OKLA] & 249 & 4.31 & 41 & 0.71 & SRS721514 \\
\hline A. notha & Nee 32966 [NY] & 432 & 7.47 & 17 & 0.29 & SRS721516 \\
\hline A. sp. nov. cf. notha & Fishbein 5816 [OKLA] & 376 & 6.45 & 16 & 0.27 & SRS721517 \\
\hline A. nyctaginifolia A. Gray & Fishbein 6268 [OKLA] & 109 & 1.92 & 23 & 0.4 & SRS721518 \\
\hline A. obovata Elliott & Lynch 11543 [OKLA] & 708 & 12.75 & 87 & 1.57 & SRS721450 \\
\hline $\begin{array}{l}\text { A. oenotheriodes Schltdl. \& } \\
\text { Cham. }\end{array}$ & Fishbein 5819 [OKLA] & 230 & 3.95 & 15 & 0.26 & SRS721519 \\
\hline A. oenotheroides & Lynch 13339 [OKLA] & 100 & 1.74 & 16 & 0.28 & SRS721521 \\
\hline A. oenotheroides & Lynch 11477 [OKLA] & 134 & 2.3 & 7 & 0.12 & SRS721523 \\
\hline A. otarioides E. Fourn. & Bellsey 97-5 [ARIZ] & 745 & 12.8 & 35 & 0.6 & SRS721520 \\
\hline
\end{tabular}




\begin{tabular}{|c|c|c|c|c|c|c|}
\hline A. otarioides & Lynch 1533 [OKLA] & 659 & 11.32 & 20 & 0.34 & SRS721522 \\
\hline A. otarioides & Fishbein 5857 [OKLA] & 697 & 11.95 & 48 & 0.82 & SRS721524 \\
\hline A. ovalifolia Decne. & Lynch 13546 [OKLA] & 333 & 5.91 & 42 & 0.75 & SRS721525 \\
\hline $\begin{array}{l}\text { A. ovata M. Martens \& } \\
\text { Galeotti }\end{array}$ & Laferrière 1478 [MO] & 324 & 5.59 & 39 & 0.67 & SRS721526 \\
\hline A. pellucida E. Fourn. & Fishbein 5136 [OKLA] & 439 & 7.53 & 9 & 0.15 & SRS721527 \\
\hline A. perennis Walter & Lynch 12408 [OKLA] & 356 & 6.11 & 15 & 0.26 & SRS721529 \\
\hline $\begin{array}{l}\text { A. pilgeriana Schltr. (“flava” } \\
\text { in Fishbein et al., 2011) }\end{array}$ & Zuloaga \& Morrone 7069 [OKLA] & 458 & 7.85 & 23 & 0.39 & SRS721528 \\
\hline A. pratensis Benth. & Fishbein 5143 [OKLA] & 410 & 7.11 & 29 & 0.5 & SRS721531 \\
\hline A. pratensis & Pérez 1850 [MO] & 609 & 10.49 & 34 & 0.59 & SRS721532 \\
\hline A. prostrata W.H. Blackw. & Fishbein 2432 [ARIZ] & 465 & 7.99 & 41 & 0.7 & SRS721533 \\
\hline A. purpurascens L. & Lynch 12847 [OKLA] & 233 & 4.05 & 22 & 0.38 & SRS721534 \\
\hline A. purpurascens & Fishbein 5654 [MISSA] & 216 & 3.73 & 7 & 0.12 & SRS721535 \\
\hline A. quadrifolia Jacq. & Webb s.n. [ARIZ] & 116 & 2.33 & 41 & 0.82 & SRS721536 \\
\hline A. quadrifolia & Fishbein 6545 [OKLA] & 204 & 3.55 & 31 & 0.54 & SRS721537 \\
\hline A. rosea Kunth & Lynch 1656 [OKLA] & 747 & 12.86 & 33 & 0.57 & SRS721538 \\
\hline A. ruthiae Maguire & Riser 329 [WS] & 31 & 0.61 & 23 & 0.45 & SRS721539 \\
\hline $\begin{array}{l}\text { A. sanjuanensis K.D. Heil, } \\
\text { J.M. Porter \& S.L. Welsh }\end{array}$ & Ellison s.n. [HPSU] & 158 & 2.96 & 33 & 0.62 & SRS721541 \\
\hline A. sanjuanensis & Fishbein 6525 [OKLA] & 237 & 4.11 & 38 & 0.66 & SRS721540 \\
\hline A. sanjuanensis & Riser 335 [WS] & 68 & 1.18 & 26 & 0.45 & SRS721542 \\
\hline A. scaposa Vail & Fishbein 2951 [ARIZ] & 500 & 8.61 & 35 & 0.6 & SRS721543 \\
\hline A. schaffneri A. Gray & Fishbein 5846 [OKLA] & 327 & 5.65 & 36 & 0.62 & SRS721545 \\
\hline A. scheryi Woodson & Fishbein 5137 [OKLA] & 586 & 10.05 & 15 & 0.26 & SRS721549 \\
\hline A. scheryi & Zamudio 5234 [MEXU] & 272 & 4.88 & 35 & 0.63 & SRS721544 \\
\hline A. similis Hemsl. & Fishbein 3000 [ARIZ] & 294 & 5.05 & 8 & 0.14 & SRS721546 \\
\hline A. similis & Fishbein 5148 [MISSA] & 386 & 6.71 & 45 & 0.78 & SRS721547 \\
\hline A. solanoana Woodson & Lynch 10884 [OKLA] & 882 & 15.13 & 35 & 0.6 & SRS721548 \\
\hline A. speciosa Torr. & Lynch 10981 [OKLA] & 242 & 4.19 & 23 & 0.4 & SRS721551 \\
\hline A. aff. standleyi Woodson & Reina 98-579 [WS] & 150 & 2.57 & 19 & 0.33 & SRS721550 \\
\hline A. subaphylla Woodson & Fishbein 3518 [WS] & 182 & 3.31 & 23 & 0.42 & SRS721552 \\
\hline A. subaphylla & Lynch 1008 [OKLA] & 383 & 6.86 & 77 & 1.38 & SRS721566 \\
\hline A. subulata Decne. & Fishbein 6434 [OKLA] & 269 & 4.64 & 7 & 0.12 & SRS721553 \\
\hline A. subulata & Fishbein 6446 [OKLA] & 370 & 6.36 & 18 & 0.31 & SRS721554 \\
\hline A. subulata $\times$ albicans & Fishbein 3142 [WS] & 299 & 5.14 & 12 & 0.21 & SRS721555 \\
\hline $\begin{array}{l}\text { A. subverticillata (A. Gray) } \\
\text { Vail }\end{array}$ & Fishbein 2948 [ARIZ] & 160 & 3.09 & 92 & 1.77 & SRS721556 \\
\hline A. syriaca L. & Lynch 11138 [OKLA] & 204 & 3.51 & 11 & 0.19 & SRS721557 \\
\hline A. syriaca & Fishbein 4885 [OKLA] & 298 & 5.1 & 7 & 0.12 & SRP005621 \\
\hline A. syriaca $\times$ speciosa & Fishbein 2810 [ARIZ] & 161 & 2.89 & 37 & 0.66 & SRS721559 \\
\hline A. tomentosa Elliott & Fishbein 5608 [MISSA] & 198 & 3.39 & 11 & 0.19 & SRS721558 \\
\hline $\begin{array}{l}\text { A. tuberosa L. ssp. interior } \\
\text { Woodson }\end{array}$ & Fishbein 2816 [ARIZ] & 685 & 11.84 & 29 & 0.5 & SRS721560 \\
\hline
\end{tabular}




\begin{tabular}{|c|c|c|c|c|c|c|}
\hline A. tuberosa ssp. interior & Fishbein 4825 [MISSA] & 297 & 5.1 & 31 & 0.53 & SRS721562 \\
\hline $\begin{array}{l}\text { A. tuberosa ssp. rolfsii } \\
\text { (Britton ex Vail) Woodson }\end{array}$ & Lynch 12526 [OKLA] & 251 & 4.33 & 11 & 0.19 & SRS721561 \\
\hline A. uncialis Greene & Fishbein 6494 [OKLA] & 282 & 4.86 & 19 & 0.33 & SRS736934 \\
\hline A. variegata $\mathrm{L}$. & Lynch 12787 [OKLA] & 375 & 6.5 & 29 & 0.5 & SRS721563 \\
\hline A. verticillata L. & Lynch 11102 [OKLA] & 23 & 0.41 & 21 & 0.37 & SRS721564 \\
\hline $\begin{array}{l}\text { A. vestita Hook. \& Arn. ssp. } \\
\text { parishii (Jeps.) Woodson }\end{array}$ & Lynch 10735 [OKLA] & 506 & 8.68 & 14 & 0.24 & SRS721565 \\
\hline A. viridis Walter & Lynch 12955 [OKLA] & 261 & 4.55 & 40 & 0.7 & SRS721567 \\
\hline A. viridula Chapm. & Fishbein 4806 [MISSA] & 425 & 7.37 & 46 & 0.8 & SRS721568 \\
\hline $\begin{array}{l}\text { A. welshii N.H. Holmgren \& } \\
\text { P.K. Holmgren }\end{array}$ & Lynch 11369 [OKLA] & 364 & 6.53 & 73 & 1.31 & SRS721570 \\
\hline $\begin{array}{l}\text { A. woodsoniana Standl. \& } \\
\text { Steyerm. }\end{array}$ & D. A. Neil 242 [MO] & 122 & 2.28 & 30 & 0.56 & SRS721569 \\
\hline
\end{tabular}


1

Polymorphic site frequency among species of Asclepias.

Histogram of polymorphic site frequency among species of Asclepias. Individuals contained from $0.4 \%$ to $15.1 \%$ polymorphic sites.

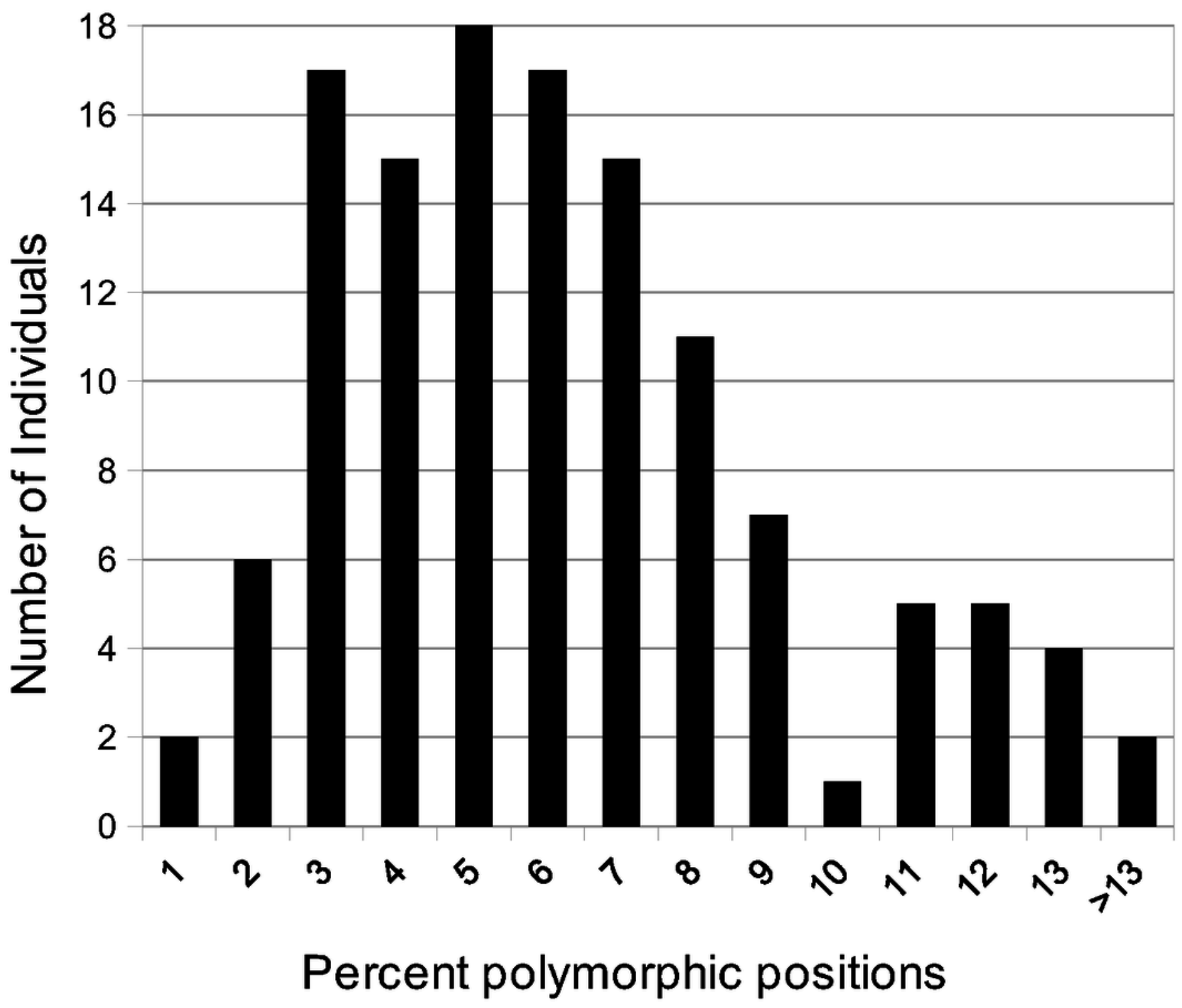


Polymorphic sites across the nrDNA cistron of Asclepias.

Number of individuals that are A) polymorphic and B) highly polymorphic at each position. Polymorphic positions are those with $\geq 2 \%$ of reads differing from the consensus; highly polymorphic positions are those with $\geq 10 \%$ differing reads. Subunit regions, white background; spacer regions, shaded background. Numbers in each region are the percentage of sites polymorphic or highly polymorphic in at least one individual.

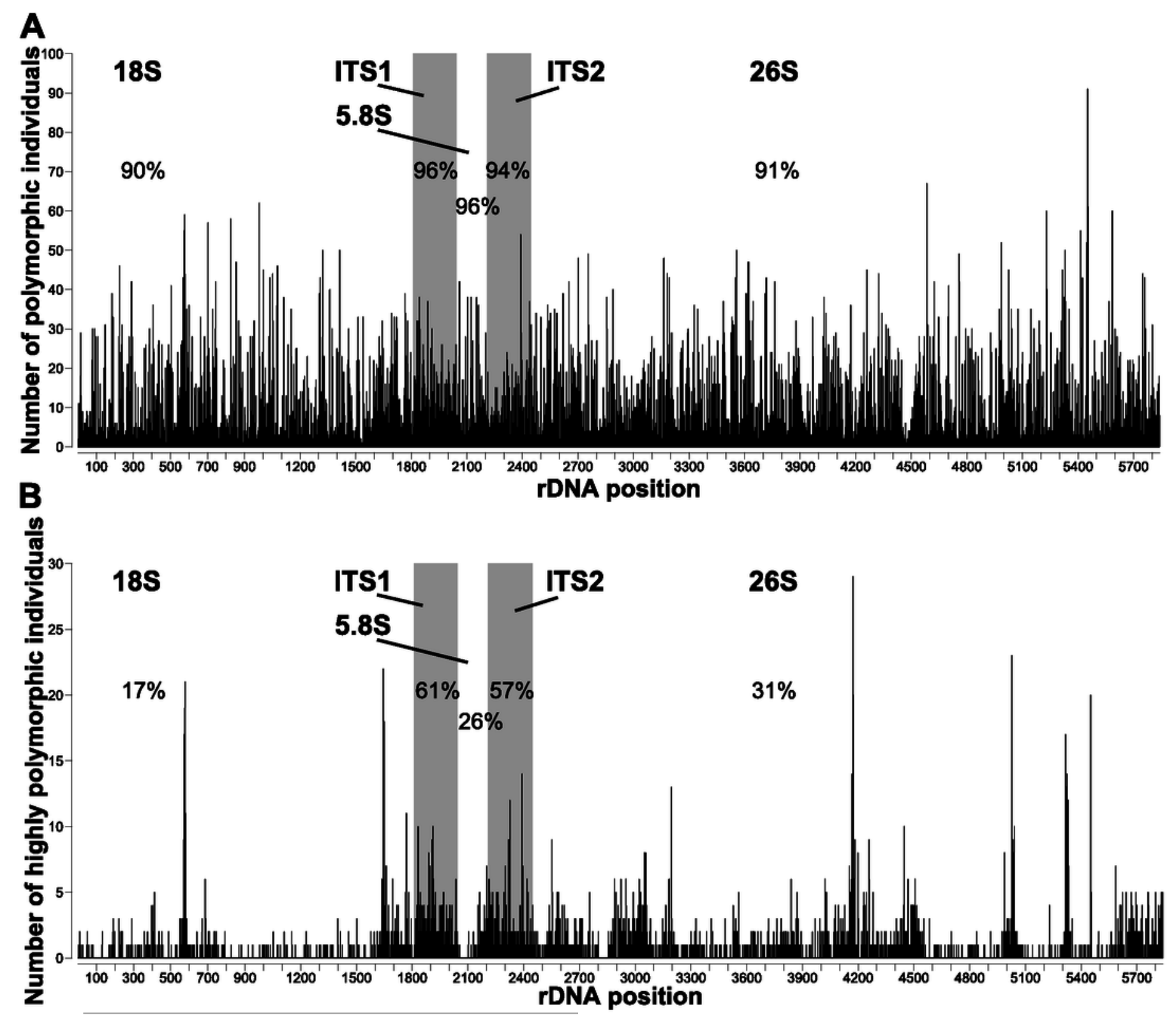




\section{3}

Polymorphism probability by region and structure.

Probability that at least one individual is A) polymorphic or B) highly polymorphic at a position that is either within a spacer (ITS1, ITS2) or subunit region (18S, 5.8S, 26S), and either paired (stems) or unpaired (loops). Error bars indicate 95\% confidence intervals. Values derived from two-factor multiple logistic regressions (Table 3).

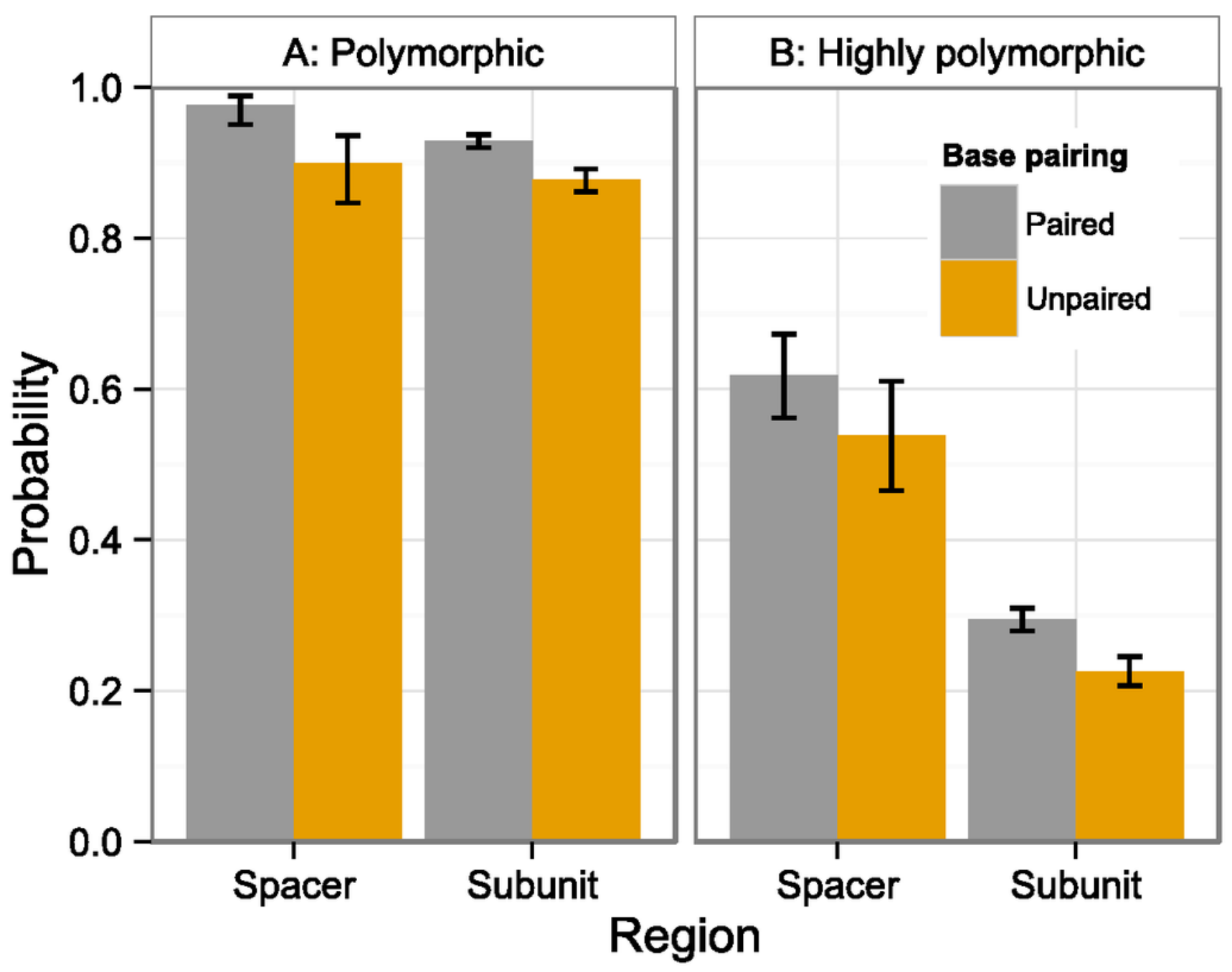


Table 2 (on next page)

ANOVA of the number of polymorphic individuals at nrDNA positions, by position type.

Two-way ANOVA of the number of polymorphic individuals at nrDNA positions categorized as either subunit (18S, 5.8S, 26S) or spacer regions (ITS1, ITS2), and as either paired (stems) or unpaired (loops). More individuals are likely to be polymorphic at sites that are in spacer regions over subunit regions, and that are paired over unpaired. Bold values indicate categories that significantly affect polymorphism abundance $(P<0.05) . d f=$ degrees of freedom. 


\begin{tabular}{l|rcrr} 
Source of variation & Sum of Squares & $d f$ & $F$ value & \multicolumn{1}{c}{$P$} \\
\hline (Intercept) & 8310.6 & 1 & & \\
Paired & 109.1 & 1 & $\mathbf{5 3 . 5 8 8 7}$ & $<\mathbf{0 . 0 0 0 1}$ \\
Subunit & 16.4 & 1 & $\mathbf{8 . 0 6 6 4}$ & $\mathbf{0 . 0 0 4 5}$ \\
Paired*Subunit & 0.4 & 1 & 0.1859 & 0.6663 \\
Residuals & 11878.9 & 5835 & &
\end{tabular}




\section{Table 3 (on next page)}

Multiple logistic regression of the likelihood of nrDNA position polymorphism, by position type.

Two-factor multiple logistic regression of the likelihood of nrDNA positions being A)

polymorphic or B) highly polymorphic in at least one individual. Positions are categorized as either within a subunit $(18 \mathrm{~S}, 5.8 \mathrm{~S}, 26 \mathrm{~S})$ or spacer region (ITS1, ITS2), and as either paired (stem) or unpaired (loop). Odds ratios indicate whether a category decreases $(<1)$ or increases $(>1)$ the likelihood a position is polymorphic or highly polymorphic. The intercept represents paired, spacer positions. Categories that significantly affect polymorphism likelihood are indicated by italics $(P<0.1)$ or boldface $(P<0.05) . \mathrm{Cl}=$ confidence interval, Std. Error $=$ standard error. Polymorphism probabilities for each category are presented in Fig. 3. 


\section{A: Polymorphic}

\begin{tabular}{c|cccccc} 
Source & Odds Ratio & $95 \% \mathrm{Cl}$ & Coefficient estimate & Std. Error & Z-value & $P$ \\
\hline (Intercept) & & & 3.7136 & 0.3825 & & \\
Subunit & $\mathbf{0 . 3 2 0}$ & $\mathbf{0 . 1 5 0 - \mathbf { 0 . 6 8 6 }}$ & $\mathbf{- 1 . 1 3 8 2}$ & $\mathbf{0 . 3 8 8 1}$ & $\mathbf{- 2 . 9 3 3}$ & $\mathbf{0 . 0 0 3 4}$ \\
Unpaired & $\mathbf{0 . 2 2 0}$ & $\mathbf{0 . 0 9 0 - \mathbf { 0 . 5 3 7 }}$ & $\mathbf{- 1 . 5 1 6 3}$ & $\mathbf{0 . 4 5 6 1}$ & $\mathbf{- 3 . 3 2 4}$ & $\mathbf{0 . 0 0 0 9}$ \\
Subunit*Unpaired & 2.488 & $0.998-6.206$ & 0.9115 & 0.4663 & 1.955 & 0.0506 \\
\hline
\end{tabular}

\section{B: Highly polymorphic}

\begin{tabular}{c|cccccc} 
Source & Odds Ratio & $95 \% \mathrm{Cl}$ & Coefficient estimate & Std. Error & Z-value & $P$ \\
\hline (Intercept) & & & 0.48551 & 0.1201 & & \\
Subunit & $\mathbf{0 . 2 5 7}$ & $\mathbf{0 . 2 0 1 - \mathbf { 0 . 3 2 9 }}$ & $\mathbf{- 1 . 3 5 8 8 1}$ & $\mathbf{0 . 1 2 5 6 4}$ & $\mathbf{- 1 0 . 8 1 5}$ & $<\mathbf{0 . 0 0 0 1}$ \\
Unpaired & 0.719 & $0.494-1.047$ & -0.32964 & 0.19178 & -1.719 & 0.0856 \\
Subunit*Unpaired & 0.970 & $0.651-1.444$ & -0.03061 & 0.20315 & -0.151 & 0.8802
\end{tabular}




\section{Table 4(on next page)}

Phylogenetic signal tests across Asclepias for the number of polymorphic or highly polymorphic sites.

Tests for phylogenetic signal across Asclepias for the number of polymorphic or highly polymorphic positions across the entire nrDNA cistron (Subunits + spacers) or just the subunits (Subunits only). Parsimony permutations: The proportion of permutations with a shorter tree length than the true data. Lambda: The maximum likelihood estimate of lambda. logL: The log-likelihood ratio of the unconstrained model including the estimated lambda over the constrained model with lambda $=0$. $\boldsymbol{P}$ : The probability of obtaining a likelihood ratio this small or smaller by chance alone. 


\begin{tabular}{|c|c|c|c|c|c|}
\cline { 3 - 5 } \multicolumn{2}{c|}{} & $\begin{array}{c}\text { Parsimony } \\
\text { permutations }\end{array}$ & Lambda & $\log L$ & $P$ \\
\hline \multirow{2}{*}{$\begin{array}{c}\text { Polymorphic } \\
\text { sites }\end{array}$} & $\begin{array}{c}\text { Subunits }+ \\
\text { spacers }\end{array}$ & $<0.0012$ & 0.51 & $\frac{-594.192}{-597.863}$ & 0.0067 \\
\cline { 2 - 6 } & Subunits only & $<0.0200$ & 0.45 & $\frac{-587.547}{-590.765}$ & 0.0112 \\
\hline $\begin{array}{c}\text { Highly } \\
\text { polymorphic } \\
\text { sites }\end{array}$ & $\begin{array}{c}\text { Subunits }+ \\
\text { spacers }\end{array}$ & $>0.6050$ & $<0.0001$ & $\frac{-387.226}{-387.225}$ & 1 \\
\cline { 2 - 6 } & Subunits only & $>0.5300$ & $<0.0001$ & $\frac{-376.150}{-376.149}$ & 1 \\
\hline
\end{tabular}


4

Ancestral state reconstruction of polymorphic site abundance.

Ancestral state reconstruction of the number of polymorphic positions in nrDNA in Asclepias obtained with squared-change parsimony. The tree topology is that pruned from Fig. 2 of Fishbein et al. (2011) with clades indicated by letters, following that study. 


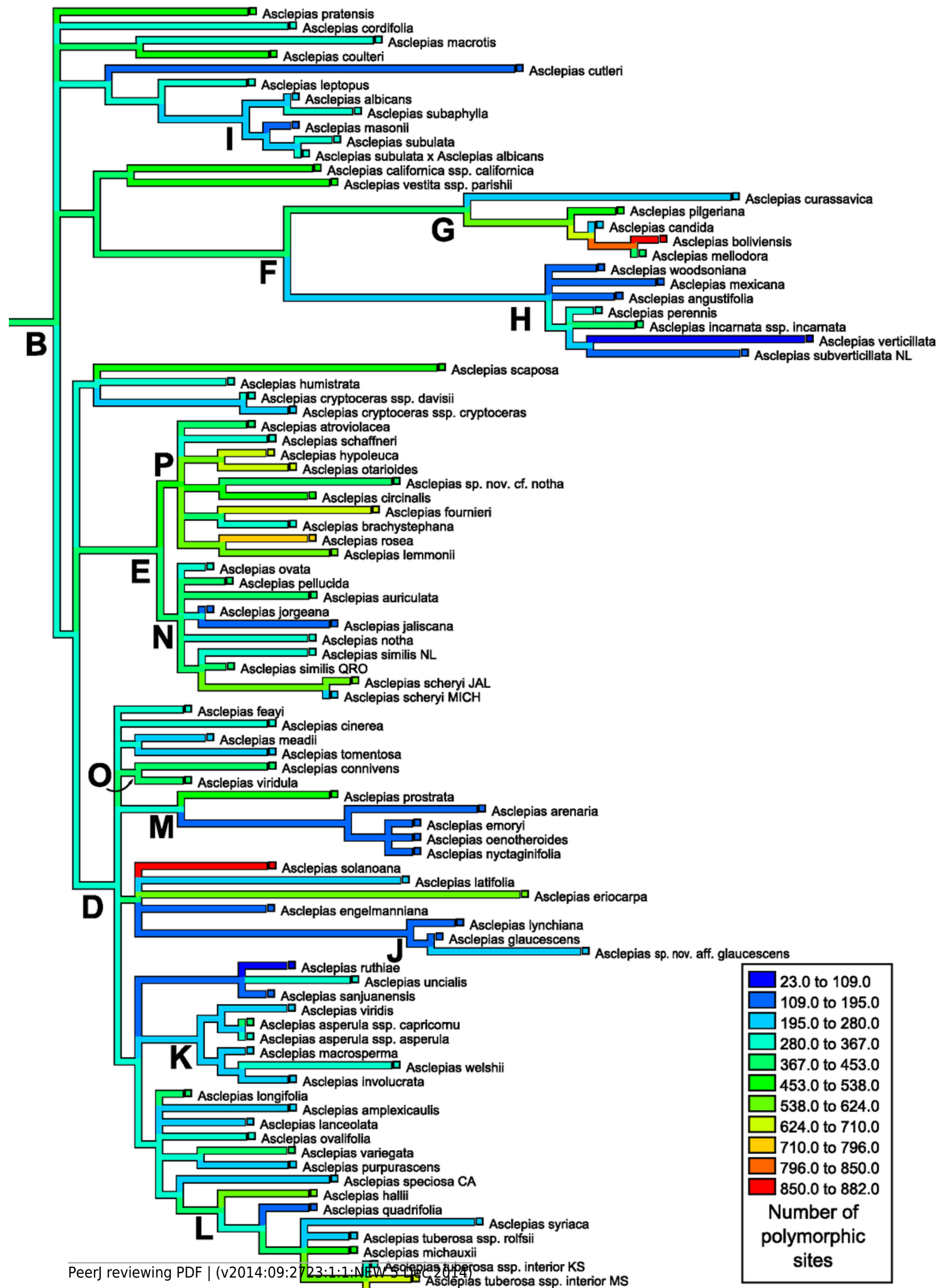




\section{5}

Ancestral state reconstruction of highly polymorphic site abundance.

Ancestral state reconstruction of the number of highly polymorphic positions in nrDNA in Asclepias obtained with squared-change parsimony. The tree topology is that pruned from

Fig. 2 of Fishbein et al. (2011) with clades indicated by letters, following that study. 


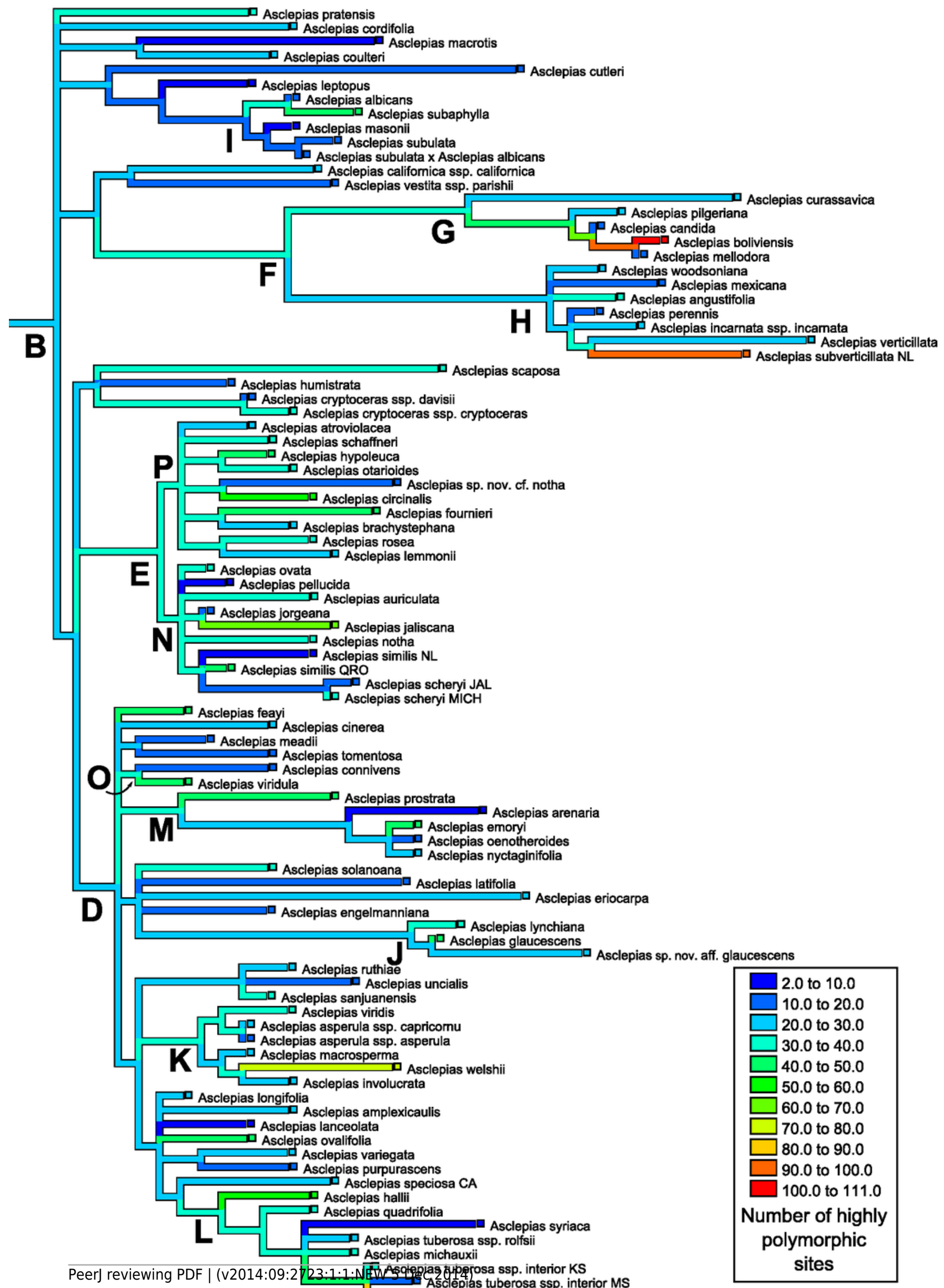

